\title{
Increased Prostacyclin Release from Perfused Hearts of Acutely Diabetic Rats
}

\author{
P. Rösen and K. Schrör \\ Abteilung für Biochemie, Diabetesforschungsinstitut an der Universität Düsseldorf, \\ and Pharmakologisches Institut der Universität Köln, FRG
}

\begin{abstract}
Summary. The release of prostacyclin and $\mathrm{PGE}_{2}$ from the isolated perfused hearts of acutely diabetic (streptozotocin $100 \mathrm{mg} / \mathrm{kg}$ ) rats was studied and compared with hearts from control animals. Prostacyclin and $\mathrm{PGE}_{2}$ were measured by a differential bioassay technique. No basal release of either prostaglandin was detected. However, after addition of arachidonic acid, a dose dependent release of prostacyclin and $\mathrm{PGE}_{2}$ was noted. Prostacyclin was identified as the major prostaglandin. Release of prostacyclin and $\mathrm{PGE}_{2}$ from acutely diabetic rat hearts was increased 2-3 times compared to control hearts. No release of prostaglandin endoperoxides was observed in either group of hearts.
\end{abstract}

Key words: Prostaglandins, prostacyclin, $\mathrm{PGE}_{2}$, perfused rat heart, prostaglandin endoperoxides, coronary flow, platelet aggregation, streptozotocin diabetes, bioassay.

Diabetic patients develop microvascular lesions and have a high incidence of thromboembolic disorders $[1,2]$. Insulin deficiency has been proposed as a factor in the pathogenesis of these events [3]. Both disturbed vascular function and increased platelet aggregability observed in diabetic patients [2] could be explained $[4,5,6]$ by increased formation of thromboxane $\mathrm{A}_{2}$ by the platelets, or decreased synthesis of prostacyclin, an inhibitor of platelet aggregation and deposition [7], by the vessel wall.

Prostacyclin is a potent vasodilator and changes in the pattern of arachidonic acid metabolites could, therefore, influence the homeostatic regulation of the microcirculation [6]. Stam and Hülsmann [8] have recently observed increased release of $\mathrm{PGE}_{2}$-like activity from the acutely-diabetic rat heart, accompanied by enhanced coronary flow. Treatment with indomethacin abolished both these effects. Because prostacyclin is known to be the major prostaglandinlike substance released by the rat heart in-vitro [9], increased prostacyclin release would be a more probable explanation for the increased flow. To test whether diabetes has a direct effect on the release of prostacyclin and prostaglandin-like substances, we have investigated prostacyclin and $\mathrm{PGE}_{2}$ release from acutely-diabetic rat hearts.

\section{Materials}

Arachidonic acid (Nu-Chek Inc., Elysian, Minnesota, > 99\% pure) was converted to the sodium salt and finally dissolved in $50 \mathrm{mmol} / 1$ Tris buffer ( $\mathrm{pH}$ 7.4). Prostacyclin and $\mathrm{PGE}_{2}$ (Upjohn Comp., Kalamazoo, Michigan) were dissolved in $0.1 \mathrm{mmol} / 1$ $\mathrm{NaOH}$ or $50 \mathrm{mmol} / 1$ phosphate buffer ( $\mathrm{pH} 7.2$ ), respectively, at $1 \mathrm{mg} / \mathrm{ml}$. Indomethacin (Merck, Sharp and Dohme, München) was dissolved in $1 \mathrm{~mol} / \mathrm{l}$ Tris buffer ( $\mathrm{pH} \mathrm{8.4)}$ and diluted with distilled water to a concentration of $0.2 \mathrm{mg} / \mathrm{ml}$. The preparation of the blocking agents is described elsewhere in detail $[12,13]$. Final concentrations were methysergide-bimaleate $20 \mathrm{mg} / \mathrm{l}$, phenoxybenzamine-hydrochloride $10 \mathrm{mg} / 1$, propranolol-hydrochloride $200 \mathrm{mg} / \mathrm{l}$, hyoscyamine-hydrobromide $10 \mathrm{mg} / \mathrm{ml}$, and mepyramine-maleate $10 \mathrm{mg} / \mathrm{ml}$. Streptozotocin (Upjohn Comp.) was freshly dissolved in $0.1 \mathrm{~mol} / 1$ citrate buffer immediately before use.

\section{Methods}

Diabetes was induced in male rats (200-260 g) with streptozotocin (100 mg/kg IP). Blood glucose was determined by a glucose oxidase method (glucose analyser, Beckman Instr.), and urinary glucose and ketones by Gluketur sticks (Boehringer, Mannheim). The rats were fasted for $20 \mathrm{~h}$ before sacrifice but had free access to water. Three days after administration of streptozotocin hearts were removed from the heparinised (250 IU) and anaesthetized ( $1500 \mathrm{mg} / \mathrm{kg}$ urethane) rats. They were perfused through the aorta 


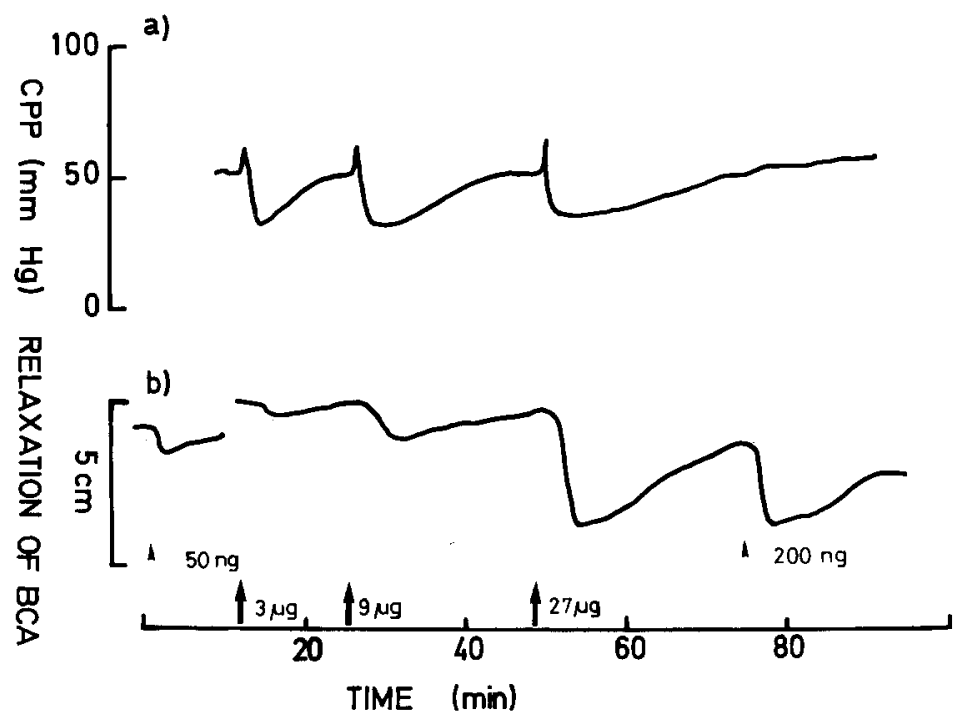

Fig. 1 a and b. Original traces of the effects of arachidonic acid injections on the coronary perfusion pressure of a diabetic heart a, and on the tone of isolated bovine coronary artery strip b superfused with the cardiac effluent. After an equilibration period of $30 \mathrm{~min}$ arachidonic acid was injected into the aortic inflow at doses and times indicated ( 1 ). Calibrating doses of prostacyclin applied directly to the assay tissue are marked $(\mathbf{\Lambda})$

using the Langendorff technique at constant flow $(8 \mathrm{ml} / \mathrm{min})$ with Krebs-bicarbonate buffer equilibrated with $5 \% \mathrm{CO}_{2}$ in $\mathrm{O}_{2}$ at $37^{\circ} \mathrm{C}$ ( $\mathrm{pH} 7.4$ ). The hearts beat spontaneously and their viability was assessed by measuring creatine phosphate $(6.2 \pm 0.3 \mu \mathrm{moles} / \mathrm{g}$ wet weight $)$ and ATP $(4.0 \pm 0.2 \mu$ moles/g wet weight, $n=10)$ content after $60 \mathrm{~min}$ perfusion. No difference in creatine phosphate or ATP content of diabetic and control hearts was observed. Coronary perfusion pressure was monitored in a branch of the aortic inflow tract.

Experiments were started (time 0 ) after a $20-30$ min equilibration period, and did not exceed $120 \mathrm{~min}$. Prostaglandin-like activities were determined in the cardiac effluent by differential bioassay using the cascade technique of Vane $[10,11]$. Bovine coronary artery strips [10] relaxed in a dose-dependent way to prostacyclin (10-200 ng), and contracted slightly in response to $\mathrm{PGE}_{2}$ at doses above $50 \mathrm{ng}$. Chick rectum [11] was dose-dependently contracted by $\mathrm{PGE}_{2}(5-100 \mathrm{ng})$ and did not respond to prostacyclin. As controls, rat-stomach strips, and in some experiments a rabbit-aorta strip, were also included. The tissues were treated with a mixture of blocking agents according to Block et al. [12], with the addition of indomethacin $(2 \mu \mathrm{g} / \mathrm{ml})$ to inhibit the endogenous formation of prostaglandin-like activities. Arachidonic acid was injected in a constant volume into a branch of the aortic inflow.

Statistical evaluation was performed by the U-test. Results are given as mean \pm SEM. Statistical significance was assumed if $p \leqslant 0.05$.

\section{Results}

Streptozotocin caused a markedly elevated blood glucose $(349 \pm 31 \mathrm{mg} / 100 \mathrm{ml} ; \mathrm{n}=12)$ as compared to controls ( $76 \pm 3 \mathrm{mg} / 100 \mathrm{ml} ; \mathrm{n}=12$ ).

Basal release of prostaglandin-like substances could not be detected either from acutely-diabetic or control hearts using the differential bioassay technique. However, arachidonic acid administration to control and diabetic hearts was followed by an immediate decrease in coronary perfusion pressure

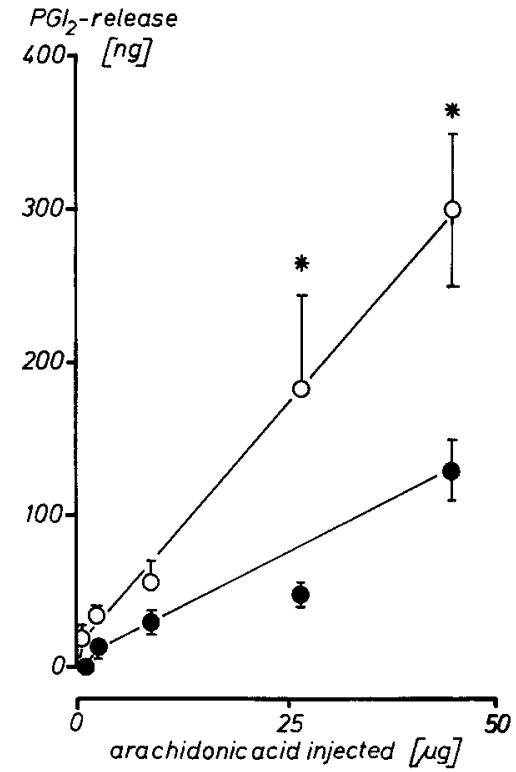

Fig. 2. Release of prostacyclin $\left(\mathrm{PGI}_{2}\right)$ from control $(\bullet, \mathrm{n}=4-6)$ and acutely-diabetic $(0, n=3-7)$ rat hearts as measured by the relaxation of bovine coronary artery strip. After an equilibration period of $20-30 \mathrm{~min}$ the hearts were perfused as described and arachidonic acid was injected into the aortic inflow at the time intervals given in Figure 1. Mean \pm SEM of $n$ observations are indicated. $*, \mathrm{p}<0.05$ when compared to the appropriate control

and the release of a substance which contracted chick rectum and rat stomach, but relaxed bovine coronary arteries. There was no contraction of rabbit aorta $(\mathrm{n}=3)$. A typical example is shown in Figure 1. Coronary perfusion pressure was already maximally reduced by the smallest dose $(3 \mu \mathrm{g})$ of arachidonic acid. The relaxation of bovine coronary artery was 


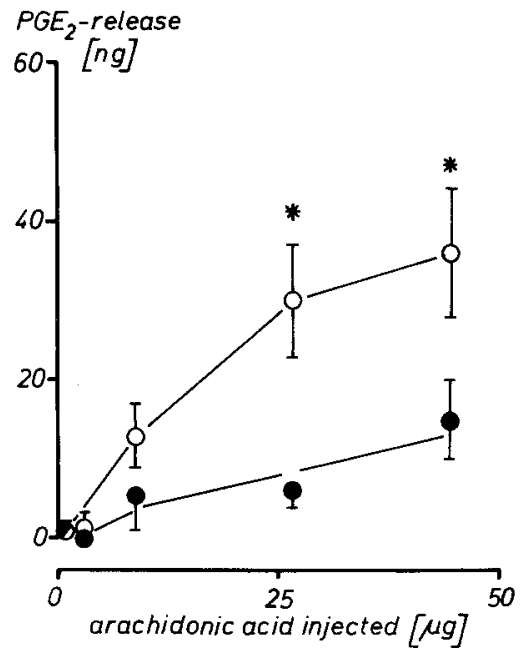

Fig. 3. Release of $\mathrm{PGE}_{2}$ from control $(\bullet, n=4-6)$ and acutelydiabetic $(\mathrm{o}, \mathrm{n}=3-7)$ rat hearts as measured by the contraction of chick rectum. Further details are given in the legend to Figure 2. Mean \pm SEM of $\mathrm{n}$ observations are indicated. $*, \mathrm{p}<0.05$ when compared to the appropriate control

Table 1. Release of prostacyclin and $\mathrm{PGE}_{2}$ from control and acutely-diabetic rat hearts after the application of $45 \mathrm{\mu g}$ arachidonic acid. Prostacyclin and $\mathrm{PGE}_{2}$ expressed as ng, mean \pm SEM

\begin{tabular}{|c|c|c|c|c|}
\hline & $\begin{array}{l}\text { Control } \\
\text { rats } \\
\mathbf{n}=3\end{array}$ & $\begin{array}{l}\text { Diabetic } \\
\text { rats } \\
n=4\end{array}$ & $\begin{array}{l}\text { Ratio } \\
\text { diabetic/ } \\
\text { control }\end{array}$ & $\begin{array}{l}\mathrm{P} \\
\text { (U-test) }\end{array}$ \\
\hline Prostacyclin & $130 \pm 19$ & $297 \pm 50$ & 2.3 & $<0.05$ \\
\hline $\begin{array}{l}\mathrm{PGE}_{2} \\
\text { Ratio }\end{array}$ & $15 \pm 5$ & $36 \pm 8$ & 2.4 & $<0.05$ \\
\hline prostacyclin/PGE 2 & 8.7 & 8.2 & 0.9 & $<0.05$ \\
\hline
\end{tabular}

dose-dependently increased by 3 to $27 \mu \mathrm{g}$ of arachidonic acid. Treating the hearts with indomethacin $(2 \mu \mathrm{g} / \mathrm{ml})$ completely prevented these effects. The dose response curves for the release of prostacyclin and $\mathrm{PGE}_{2}$-like activities by hearts from acutely diabetic and control rats are shown in Figures 2 and 3. At all doses of arachidonic acid, prostacyclin was the major prostaglandin-like substance released from normal and diabetic heart. For diabetic hearts the prostacyclin release increased from below $10 \mathrm{ng}$ up to $300 \mathrm{ng}$ depending on the amount of arachidonic acid, whereas the maximum $\mathrm{PGE}_{2}$-like activity detected was $36-40 \mathrm{ng}$. The ratio of prostacyclin to $\mathrm{PGE}_{2}$ was the same in diabetic and control hearts. At all arachidonic acid doses the responses of the diabetic hearts were greater than that of the controls. Arachidonic acid $(45 \mu \mathrm{g})$ released $297 \pm 50 \mathrm{ng}$ of prostacyclin-like activity from diabetic hearts, significantly more than the $130 \pm 19$ ng released by control hearts $(p<0.05)$. At the same dose there was a release of $36 \pm 8 \mathrm{ng}$ of $\mathrm{PGE}_{2}$-like activity from the diabetic hearts, compared to only $15 \pm 5 \mathrm{ng}$ in controls $(\mathrm{p}<0.05)$. Table 1 summarises the results for the $45 \mu \mathrm{g}$ dose of arachidonic acid.

\section{Discussion}

Infusion of arachidonic acid produces a dose-dependent release of prostacyclin and $\mathrm{PGE}_{2}$ from both acutely diabetic and control hearts. Prostacyclin was the major prostaglandin released from hearts of both groups, confirming results from other studies of prostaglandin release from isolated hearts of several animal species $[9,13,14]$. The ratio prostacyclin/PGE 2 ranged between 8 and 9 being apparently independent of the dose of arachidonic acid applied. These results, and the lack of prostaglandin endoperoxide release (as evidenced by the absence of rabbit aorta contracting substance), suggest that in the dose range studied, saturation of the metabolic conversion of prostaglandin endoperoxides into prostacyclin and $\mathrm{PGE}_{2}$ was not achieved. These findings differ from earlier studies with rabbit and guinea-pig hearts, in which maximum release of prostacyclin and $\mathrm{PGE}_{2}$ was obtained at lower doses of arachidonic acid $(10 \mu \mathrm{g})$, and release of prostaglandin endoperoxides occured $[13,14]$. The higher capacity of rat hearts to produce prostaglandins cannot be explained. Measurements of the appropriate enzymes (prostaglandin-cyclooxygenase, prostacyclin synthetase, $\mathrm{PGE}_{2}$-isomerase) should clarify this.

The increased release of prostacyclin and $\mathrm{PGE}_{2}$ in the acutely-diabetic rat heart might be explained by better availability of the exogenous arachidonic acid because of increased vascular permeability [1]. Basal release of prostaglandin-like substances was not measured because of the low concentrations released, but there are some indications that the basal release is increased in acutely-diabetic hearts. Stam and Hülsmann [8] have shown inhibition of the higher coronary flow of diabetic hearts with indomethacin. The higher coronary flow of diabetic hearts may be explained by the observed increase in the formation of prostacyclin rather than the synthesis of $\mathrm{PGE}_{2}$. Furthermore, these findings could help to explain the diminished aggregability of platelets of streptozotocin-diabetic rats [15].

There are several reports dealing with decreased prostacyclin formation in diabetes $[16,19,20]$. It should be noted, however, that these experiments have been performed on preparations of large ves- 
sels, whereas our experiments were done on a complete organ circulation including small arteries and veins. It has been shown that the endothelial surface is enhanced in arterioles of diabetic animals but diminished in the larger vessels [18]. This morphological data could explain these apparently divergent observations. Moreover, because local perfusion is regulated by small vessel tone, changes in prostacyclin release by these vessels could be more relevant to the vascular disturbances of diabetes.

\section{References}

1. Brownlee M, Cahill GF (1979) Diabetic control and vascular complications. In: Paoletti R (ed) Atherosclerosis reviews, vol 4. Raven Press, New York, p 29-70

2. Colwell JA, Chambers A, Laimins M (1975) Increased platelet aggregation in early diabetes. Diabetes 24: 684-687

3. Fraser R, Lowy C, Elkeles RS, Lewis B, Mancini M (1973) Insulin, glucose and lipid levels in mild diabetes in regulation to complications. In: Camerini-Davalos RA, Cole HS (eds) Vascular and neurological changes in early diabetes. Academic Press, New York, p 83-93

4. Hamberg M, Svensson J, Samuelsson B (1975) Thromboxanes: A new group of biologically active compounds derived from prostaglandin endoperoxides. Proc Natl Acad Sci USA 74: 2994-2998

5. Ellis E, Oelz O, Roberts J, Payne N, Oates J (1976) Coronary arterial smooth muscle contracted by a substance released by platelets: evidence that it is thromboxane $A_{2}$. Science 193: 638-643

6. Moncada S, Vane JR (1977) The discovery of prostacyclin (PGX). A fresh insight into arachidonic acid metabolism. In: Kharasch N, Fried J (eds) Interscience Prostaglandin Symposium. Academic Press, New York San Francisco London, p 155-177

7. Moncada S, Vane JR (1979) Arachidonic acid metabolism and the interactions between platelets and blood vessel wall. $\mathrm{N}$ Engl J Med 300: 1142-1147

8. Stam H, Hülsmann WC (1977) Effect of fasting and streptozotocin-diabetes on the coronary flow in isolated rat hearts: a possible role of endogenous catecholamines and prostaglandins. Basic Res Cardiol 72: 365-375

9. De Deckere EAM, Nugteren DH, Ten Hoor T (1977) Prostacyclin is the major prostaglandin released from the isolated perfused rabbit and rat heart. Nature 268: 160-163
10. Dusting GJ, Moncada S, Vane JR (1977) Prostacyclin is an endogenous metabolite of arachidonic acid which relaxes coronary arteries. Prostaglandins 13: 3-15

11. Vane JR (1969) The release and fate of vasoactive hormones in the circulation. Br J Pharmacol 35: 209-242

12. Block AJ, Feinberg H, Herbaczynska-Cedro K, Vane JR (1975) Anoxia-induced release of prostaglandins in rabbit isolated hearts. Circ Res 36: 34-42

13. Schrör K, Moncada S, Ubatuba FB, Vane JR (1978) Transformation of arachidonic acid and prostaglandin endoperoxides by guinea-pig heart. Formation of RCS and prostacyclin (PGX). Eur J Pharmacol 47: 103-114

14. Schrör K, Moncada S, Ubatuba FB, Vane JR (1977) Formation of prostacyclin (PGX) causes decrease in the coronary vascular resistance during application of arachidonic acid. Naunyn Schmiedebergs Arch Pharmacol 297: R 31

15. Eldor A, Merin S, Bar-On H (1978) The effect of streptozotocin diabetes on platelet function in rats. Thromb Res 13: $703-714$

16. Harrison HE, Reece AH, Johnson M (1978) Decreased vascular prostacyclin in experimental diabetes. Diabetologia 14: 237

17. Gryglewski RJ, Dembinska-Kiec A, Zmuda A, Gryglewska T (1978) Prostacyclin and thromboxane $A_{2}$ biosynthetic capacities of heart, arteries and platelets at various stages of experimental atherosclerosis in rabbits. Atherosclerosis 31: 385-394

18. Bohlen HG, Niggl BA (1979) Arteriolar anatomical and functional abnormalities in juvenile mice with genetic or streptozotocin-induced diabetes mellitus. Circ Res 45: 390-396

19. Moncada S, Higgs EA, Vane JR (1977) Human arterial and venous tissues generate prostacyclin, a potent inhibitor of platelet aggregation. Lancet I: $18-20$

20. Silberbauer K, Schernthaner G, Sinzinger H, Piza-Katzer H (1979) Decreased vascular prostacyclin in juvenile onset diabetics. N Engl J Med 300: 366-367

Received: June 11, 1979, and in revised form: November 19, 1979

\author{
P. Rösen \\ Abteilung für Biochemie \\ Diabetesforschungsinstitut an der Universität \\ Auf'm Hennekamp 65 \\ D-4000 Düsseldorf \\ Federal Republic of Germany
}

Note added in proof. Recently, Buchanan et al. (1979) reported marked variations in the prostacyclin synthesis depending on the time lapse between vessel wall preparation and measuring prostacyclin, presumably because of thrombin formation induced by mechanical trauma during the preparation procedure. Therefore, these authors recommend to heparinize the animals prior to their death. In contrast to the reported results, studies describing a decreased prostacyclin formation $[16,19,20]$ were performed with vessel wall preparations from unheparinized animals. This methodological difference may be of relevance for the observed divergent results in our and the cited studies.

Buchanan MR, Dejana E, Cazenave JP, Mustard JF, Hirsh J (1979) Uncontrolled PGI 2 production by whole vessel wall segments due to thrombin generation in vivo and its prevention by heparin. Thromb Res 16: 551-555 